\title{
Sistem penjernih air limbah rumah tangga dengan kendali PID berbasis arduino
}

\author{
Mokh. Sholihul Hadi ${ }^{1}$, Alfin FIrmanSyah ${ }^{2}$, Fatma Cahyaningrum ${ }^{3}$, Ahmad Sariful Anwar ${ }^{4}$, \\ Dwi Arini Mufarichah ${ }^{5}$
}

1. Universitas Negeri Malang, Indonesia | mokh.sholihul.ft@um.ac.id

2. Universitas Negeri Malang, Indonesia | alfinfirmansyah11@gmail.com

3. Universitas Negeri Malang, Indonesia | fatmacahya12@gmail.com

4. Universitas Negeri Malang, Indonesia | sariful96@gmail.com

5. Universitas Negeri Malang, Indonesia | dwi.arinims@gmail.com

\begin{abstract}
Abstrak
Penelitian membuat alat penjernih air limbah rumah tangga menggunakan s/stem kendali PID berbasis Arduino. Sistem ini terdiri dari penggabungan teknologi penjernih air yang sudah ada dengan teknologi mikrokontroler yang dapat menjalankan sistem secara otomatis. Pada wadah penyaringan atau water treatment terdiri dari bahan-bahan alami yaitu tawas, batu zolit, batukali, ziloit pasir, batu apung, pasir silica, karang jahe, karbon aktif. Setelah melalui penyaringan air akan diukur kejernihannya menggunakan sensor LDR, apabila air tersebut masih keruh maka akan dipompa kembali ke dalam wadah penyaringan kembali. Air yang telah melewati alat penjernih ini dapat digunakan ulang untuk non konsumsi sehari hari. Berdasarkan hasil pengujian, didapatkan set poin terbaik pada $518, k p=1, k i=0.2, k d=0.01, T s=0.1$. Hasil pengujian skala laboratorium untuk tingkat kekeruhan air hasil treatment menggunakan prototipe sistem ini didapatkan angka 2.48 NTU yang merupakan indikasi air yang dijernihkan tersebut layak untuk dikonsumsi.
\end{abstract}

\section{Kata kunci}

Arduino, PID, Penjernih air limbah rumah tangga, sensor LDR 


\section{TEKNO Junal Teknologi, Elektro, dan kejivuan}

http://journal2.um.ac.id/index.php/tekno | ISSN 1693-8739

\section{PENDAHULUAN}

Air merupakan kebutuhan yang sangat diperlukan bagi kehidupan makhluk hidup terutama manusia. Kebutuhan air pada manusia diantaranya untuk mandi, mencuci, memasak dan lain sebagainya. Begitu juga makhluk hidup lainnya, jika air limbah rumah tangga mencemari pembuangan air terakhir yaitu sungai terminum oleh ekosistem di dalam maupun di luar sungai, maka akan mengganggu kesehatan makhluk hidup tersebut. Seperti kasus yang ditulis oleh Rosmidah Hasibuan pada jurnal IImiah "Advokasi” Vol. 04. No. 01. Maret 2016 yang berjudul Analisis Dampak Limbah atau Sampah Rumah Tangga Terhadap Pencemaran Lingkungan Hidup yang mengatakan bahwa dampak limbah rumah tangga dapat mempengaruhi terhadap pencemaran lingkungan seperti penurunan kualitas air (Hasibuan, dkk 2016). Begitu juga seperti yang telah ditulis oleh Kadek Diana dan I G. M. Konsukartha pada jurnal pemukiman natah yang berjudul Pencemaran Air Tanah Akibat Pembuangan Limbah Domestik di Lingkungan Kumuh, mengatakan bahwa di daerah Banjar Ubung Sari, pola penyebaran penduduknya tidak merata dan volume penduduk pendatangnya cukup besar. Hal ini mengakibatkan makin berkembangnya pemukiman-pemukiman yang kurang terencana dengan baik dan kurang terencana sehingga dapat mengakibatkan system pembuangan limbah rumah tangga seperti pembuangan limbah kamar mandi atau wc dan dapur tidak terkondisi dengan baik. Limbah tersebut dapat berakibat pada pencemaran air tanah yang dapat mengakibatkan terjadinya penyebaran beberapa penyakit menular (Diana dkk, 2007).

Limbah rumah Tangga akan sangat berpengaruh sekali pada ekosistem yang hidup di sungai Wicaksono, S. 2017, karena air sungai yang akan terkontaminasi oleh air limbah rumahan akan mempercepat pertumbuhan eceng gondok dan mengkontaminasi ph air tersebut. Dengan eceng gondok yang semakin banyak yang tumbuh di sungai maka hewan yang hidup di dalam sungai akan kehabisan oksigen dan mati. Itu akan berpengaruh pada masyarakat menengah kebawah yang mana pekerjaannya mencari ikan di sungai akan terganggu perekonomiannya. Selain untuk menanggulangi adanya pencemaran pada sungai dengan adanya alat penjernih air ini akan menambah persediaan air bersih bagi manusia terutama untuk masyarakat yang hidup di desadesa yang kekurangan air bersih.

Penelitian ini membahas tentang penjernihan air sungai yang ditampung dalam wadah yang secara otomatis akan tersaring dan jernih dengan penyaringan menggunakan sistem kendali PID berbasis Arduino. Sistem akan diimplementasikan di rumah-rumah yang kebutuhan sehariharinya angka pemakaian air bersihnya tinggi dan menggunakan sungai sebagai sumber air konsumsi. Air yang dijernihkan dapat digunakan ulang untuk berbagai keperluan selain untuk dikonsumsi.

\section{METODE PENELITIAN}

Penelitian ini menggunakan metodologi, penelitian yang mencangkup studi pustaka, sistem yang dibuat berdasarkan pada referensi yang telah ada dan dilakukan pengembangan lebih lanjut. Kemudian dilakukan analisa kebutuhan akan komponen komponen yang digunakan dalam pembuatan sistem penjernih air limbah rumahan dengan kendali PID berbasis Arduino(Hadi dkk, 


\section{TEKNO Jumal Teknologi, Eektro, dan Kkijuran}

http://journal2.um.ac.id/index.php/tekno | ISSN 1693-8739

2017). Tahap berikutnya adalah perancangan sistem, kemudian dilakukan tahap integrasi dan pengujian. Terakhir adalah tahap analisis dan penerapan.

\section{PERANCANGAN SISTEM}

Tahap perancangan yang dilakukan dalam penelitian ini meliputi pembuatan blok diagram sistem, perancangan perangkat keras dan perancangan perangkat lunak dari prototype penjernih air limbah rumahan.

\section{Blok Diagram Sistem}

Penelitian pada system yang telah kami buat ini menggunakan Arduino Uno R3 sebagai pengendali utama system. Dimana Arduino Uno R3 akan menerima data dari sensor LDR jika air yang telah tersaring pada water treatment masih kotor maka Arduino akan mengirimkan data pada relay untuk menghidupkan pompa agar air kembali tersaring ke water treatment sampai air yang di deteksi oleh sensor LDR bersih atau tidak lagi keruh, blok diagram dapat dilihat pada Gambar 1.

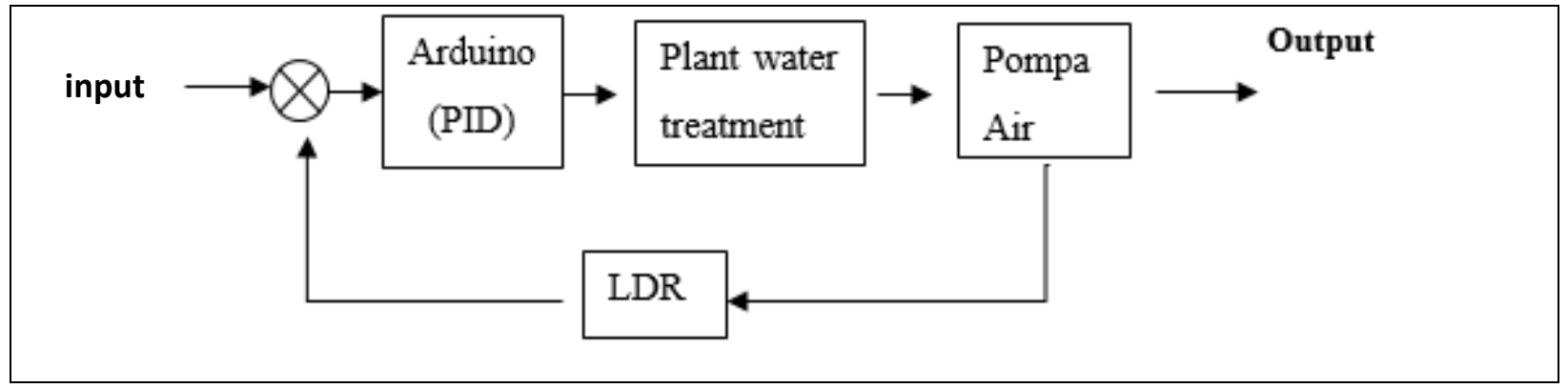

Gambar 1. Blok Diagram Sistem

\section{Perancangan Perangkat Keras}

Peranangan perangkat keras dimulai dengan merancang prinsip kerja alat, dilanjutkan dengan merancang rangkaian alat dengan meng- integrasikan beberapa perangkat menjadi sebuah system, yang mana terdiri dari Arduino Uno R3, plant water treatment, sensor LDR, relay dan pompa air.

Perangkat keras yang dgunakan dalam rancang bangun prototype alat penjernih air limbah rumahan dengan system kendali PID berbasis Arduino adalah sebagai berikut:

a. Arduino Uno R3 (Megawati dkk, 2016) yang berfungsi sebagai pengendali utama, Arduino ini bekerja sesuai dengan program yang telah dibuat

b. Sensor LDR yang berfungsi sebagai pendeteksi kejernihan air yang terletak pada wadah penampungan setelah air keruh melalui plant water treatment

c. Relay berfungsi untuk penghubung dan pemutus aliran arus listrik untuk mengendalikan pompa air.

d. Pompa air berfungsi untuk memompa air yang terdeteksi oleh sensor LDR jika kurang jernih maka akan dipompa kembali menuju wadah plant water treatment. 


\section{TEKNO Jumal Teknologi, Eektro, dan Kejivuan}

http://journal2.um.ac.id/index.php/tekno | ISSN 1693-8739

e. Plant water treatment berfungsi untuk menyaring air keruh menjadi air yang bersih dan dapat digunakan untuk kehidupan non konsumsi, menggunakan botol bekas yang di dalamnya terdapat bahan bahan alami yang disusun secara vertical. Untuk penyaringannya digunakan bahan-bahan alami yang terdiri dari tawas, batu ziolit, batu kali, batu apung, pasir silica, karang jahe, karbon aktif, yang disusun pada wadah tabung vertikal. Untuk gambar wadah penyaringan atau plant water treatment yang digunakan dapat dilihat pada gambar 2 .

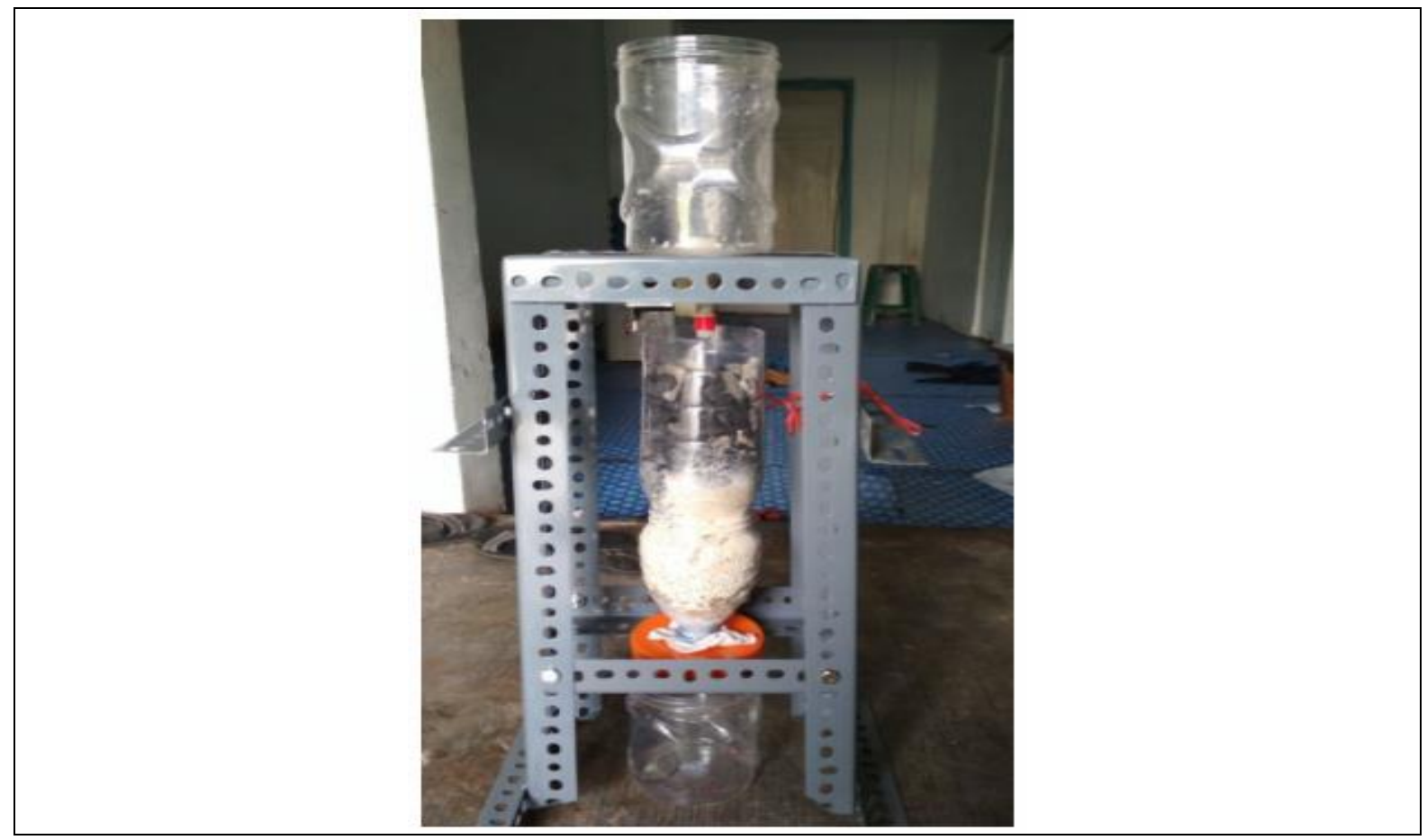

Gambar 2. Plant water treatment.

\section{Perancangan Perangkat Lunak}

Pada penelitian ini dilakukan perancangan algoritma pemrograman yang kemudian akan diintegrasikan menjadi sebuah system perangkat keras yang telah dirancang sebelumnya, diagram alur pemrograman dapat dilihat pada Gambar 3. Yang artinya yaitu dimulai dari air limbah masuk ke water treatment yang disana akan mengalami penjernihan air yang menggunakan bahan bahan alami seperti karbon aktif, karang jahe, pasir silica, batu agung, ziloit pasir, batu kali, batu ziloid dan tawas. Setelah itu ai yang telah melalui plant water treatment tertampung pada wadah bening di bawah plant water treatment. Pada saat air berada pada wadah bening tersebut sensor LDR membaca kejernihan air, jika air setelah disaring ternyata masih keruh maka akan mengaktifkan pompa dan pompa membawa air ke wadah water treatment, terus seperti itu sampai hasil saringannya jernih. Namun apabila tidak keruh atau air tersebut jernih maka akan berakhir atau tidak mengaktifkan pompa. 


\section{TEKNO Jumal Teknologi, Eektro, dan Kejivruan}

http://journal2.um.ac.id/index.php/tekno | ISSN 1693-8739

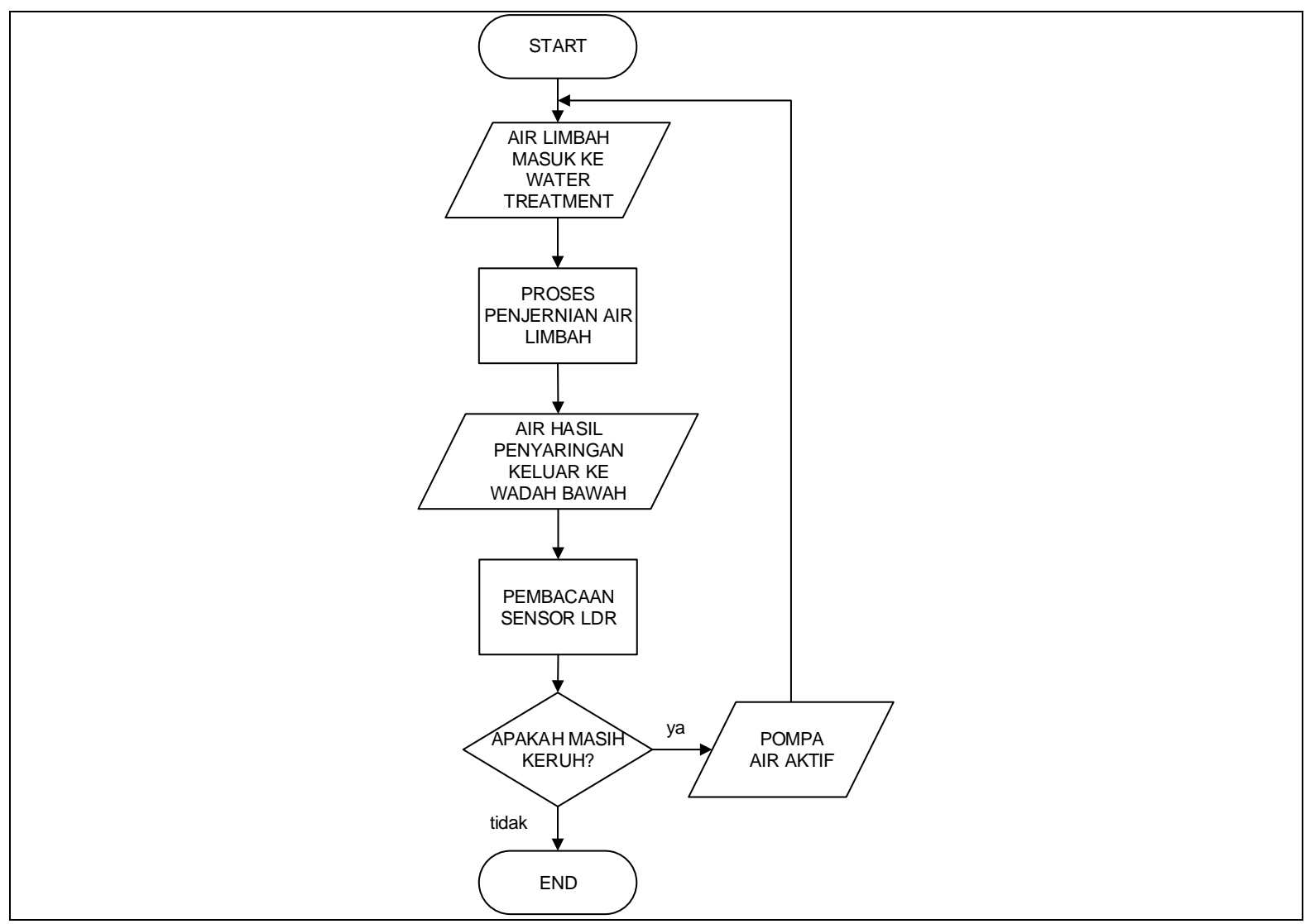

Gambar 3. Diagram alir Perangkat Lunak sistem

Software yang digunakan pada system ini adalah Arduino. Logika control PID dituliskan dalam source code program yang dapat dilihat pada Gambar 4. 


\section{TEKNO Jurnal Teknologi, Elektro, dan Kejuruan}

http://journal2.um.ac.id/index.php/tekno | ISSN 1693-8739

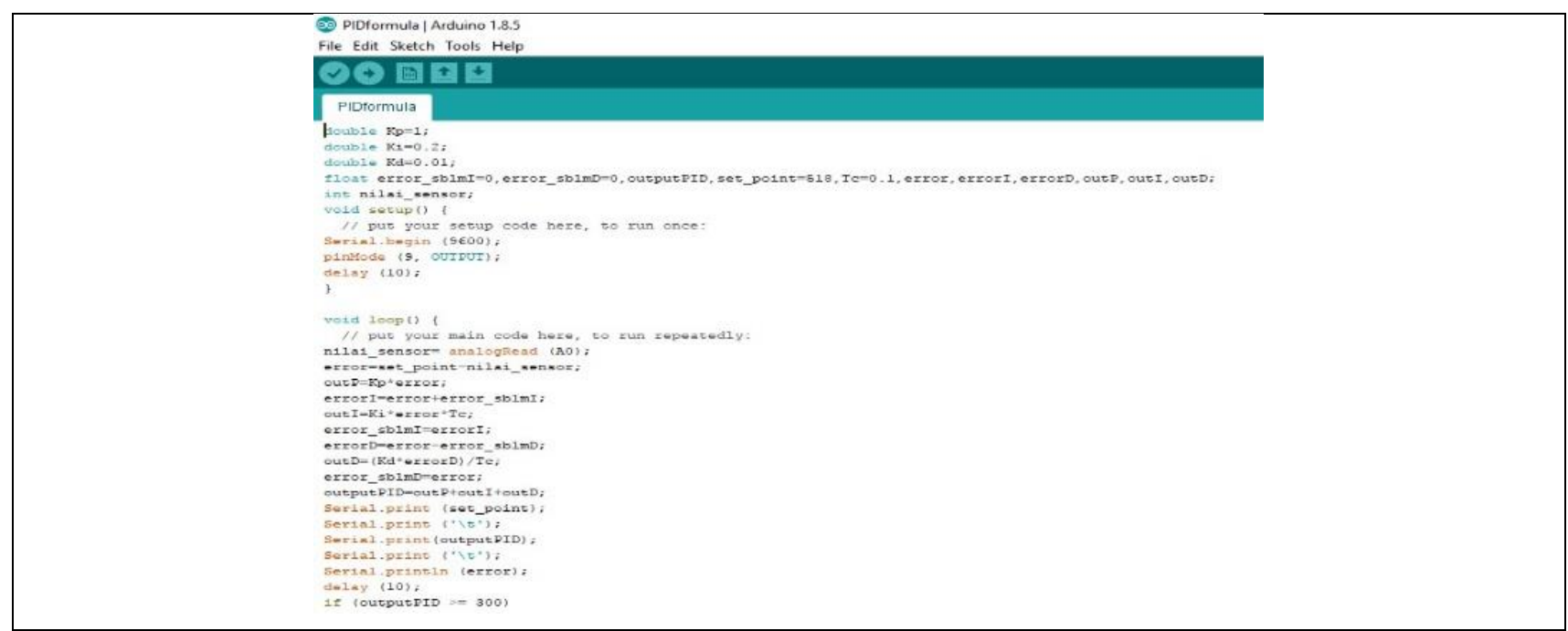

Gambar 4. Source code program

Dalam menentukan komposisi nilai Kp, Ki, Kd menggunakan metode trial error. Variasi angkaangka yang dimasukkan sebagai nilai $\mathrm{Kp}, \mathrm{Ki}, \mathrm{Kd}$ mempertimbangkan sifat dari respon system. Dikarenakan metode ini tidak dapat memberikan jaminan kebenaran terhadap nilai yang dihasilkan maka dilakukan validasi terhadap masing-masing variasi nilai $\mathrm{Kp}, \mathrm{Ki}$, Kd dengan melihatrespon sistemnya kemudian dianalisa mana yang mampu menghasilkan respon system terbaik. Nilai Kp, Ki, Kd yang mampu menghasilkan respon terbaik maka nilai tersebut yang digunakan. Pemrograman control PID yang digunakan dalam penelitian ini adalah adaptive tuning. Dalam adaptive tuning terdapat dua kondisi yang ditetapkan yaitu jauh atau dekat nilai output sensor dari set point yang telah di tentukan. Nilai Kp, Ki, Kd yang ada pada dua ondisi tersebut akan berbeda beda. Kondisi pertama apabila output jauh dari set point, sedangkan kondisi kedua apabila output dekat dengan set point (Marhi dkk, 2014)(Gerry, 2005).

\section{HASIL PENGUJIAN}

\section{Pengambilan Data}

Sensor yang digunakan pada prototype penjernih air limbah rumah tangga ini adalah sensor LDR yang dapat mengukur kejernihan air melalu terang tidaknya atau banyaknya cahaya yang tertangkap oleh sesnsor LDR. Cahaya yang digunakan pada pengujian untuk ditangkap oleh LDR adalah cahaya LED. Apabila air keruh maka akan sedikit cahaya yang ditangkap sensor LDR, dan sebaliknya apabila jernih maka akan banyak cahaya yang ditangkap oleh sensor LDR.

Penetapan set point dilakukan dengan cara melakukan uji coba terus menerus hingga mendapatkan respon terbaik. Penguji coba alat ini sebanyak 15 kali mendapatkan set point yaitu $518, k p=1, k i=0.2, k d=0.01, T s=0.1$.

Apabila sensor LDR membaca bahwa air keruh maka resistansi LDR akan naik dan Arduino memerintahkan untuk mengaktifkan relay agar pompa menyala, dan apabila sensor LDR membaca bahwa air tersebut telah jernih, maka resistansi LDR akan turun dan Arduino memerintakan relay agar tidak aktif, agar pompa tidak membawa air ke water treatment. 


\section{TEKNO Jumal Teknologi, Eektro, dan Kejivruan}

http://journal2.um.ac.id/index.php/tekno | ISSN 1693-8739

\section{Pengujian Respon}

Kontroler system yang menggunakan logika PID yang telah dituliskan pada source code Arduino. Dalam menentukan komposisi nilai Kp, Ki, Kd menggunakan metode trial error. Variasi angka-angka yang dimasukkan sebagai nilai $\mathrm{Kp}, \mathrm{Ki}$, Kd mempertimbangkan sifat dari respon system. Dikarenakan metode ini tidak dapat memberikan jaminan kebenaran terhadap nilai yang dihasilkan maka dilakukan validasi terhadap masing-masing variasi nilai Kp, Ki, Kd dengan melihatrespon sistemnya kemudian dianalisa mana yang mampu menghasilkan respon system terbaik.

Pada Gambar 5., Gambar 6., dan Gambar 7., merupakan respon kendali PID pada nilai tuning terbaik. Pada Gambar 5. Merupakan grafik respon sistem ketika keruh, pada Gambar 6. merupakan grafik respon sistem ketika air jernih setelah melali water treatment. Dan Gambar 7. yaitu grafik respon sistem ketika air jernih tanpa pengaruh apapun yang artinya kondisi air jernih tanpa perlu melalui water treatment.

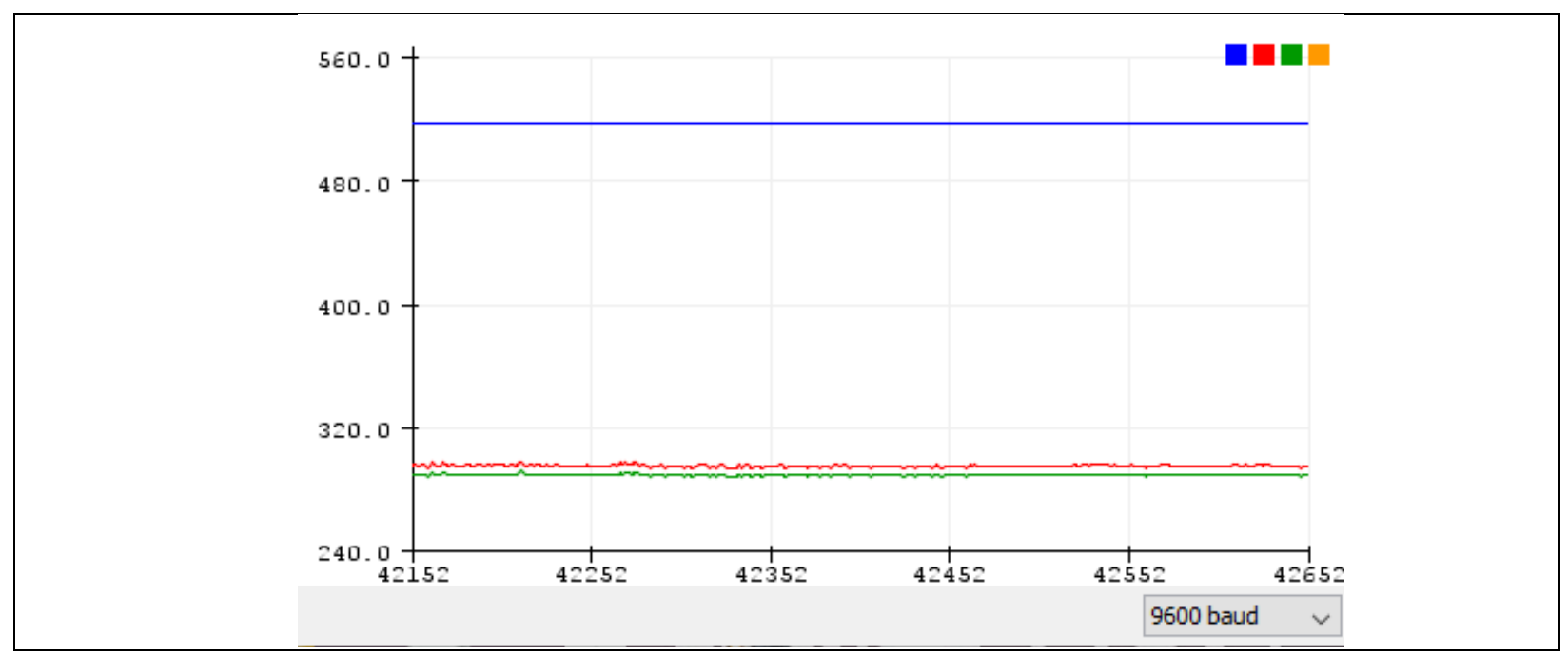

Gambar 5. grafik respon sistem ketika air keruh 


\section{TEKNO Jumal Teknologi, Ekekro, dan Kejuruan}

http://journal2.um.ac.id/index.php/tekno I ISSN 1693-8739

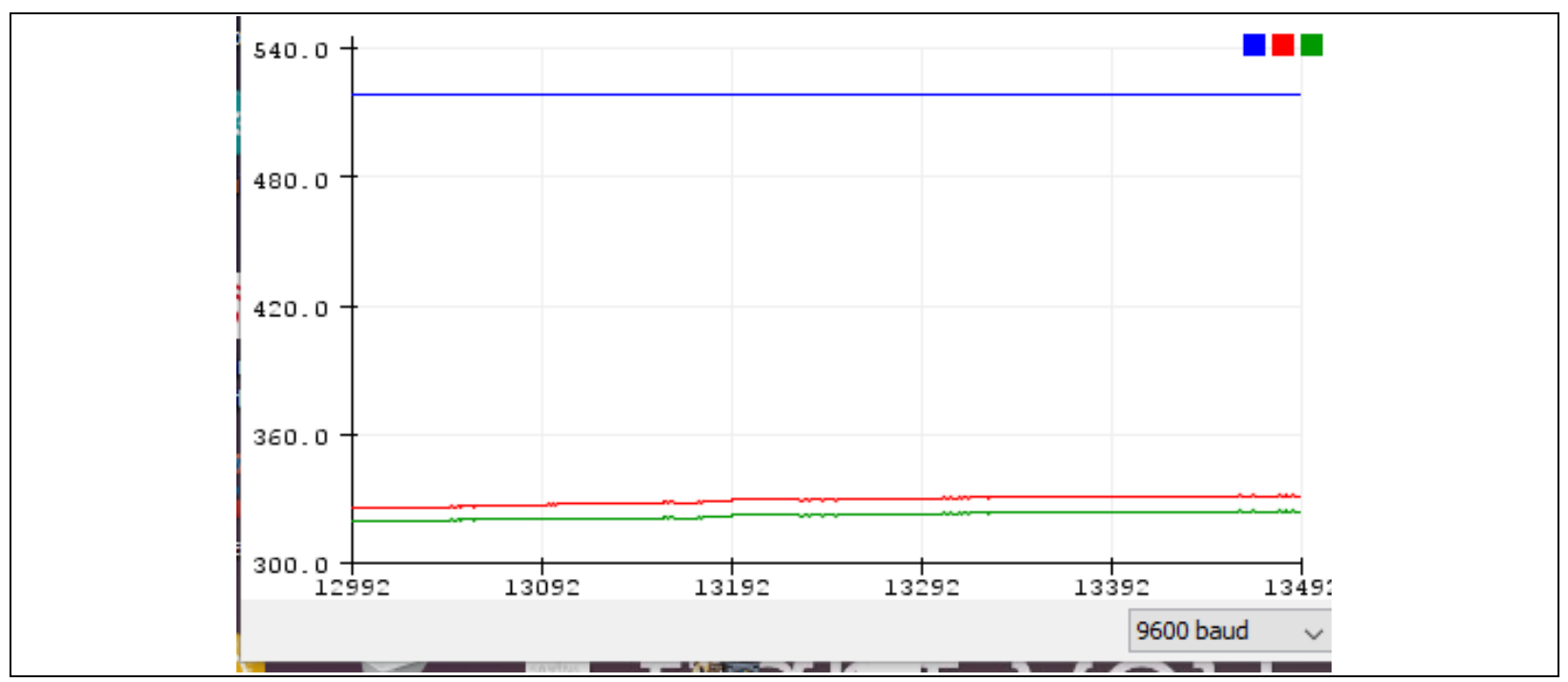

Gambar 6. grafik respon sistem ketika jernih (keluaran water treatment)

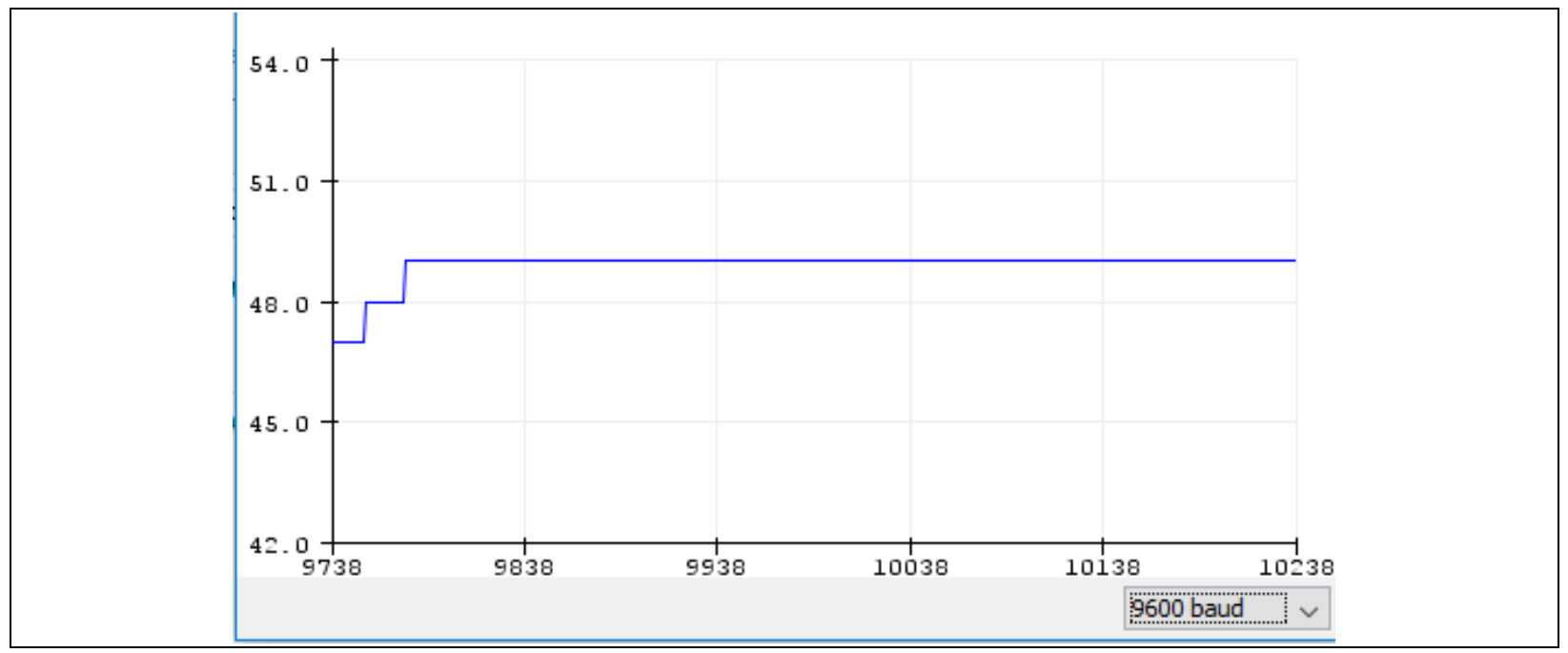

Gambar 7. grafik respon sistem ketika air jernih tanpa pengaruh apapun

Tabel 1. Data Hasil Penelitian

\begin{tabular}{ccc}
\hline Keterangan & PID & Angka terukur \\
\hline Keruh & 500 & 490 \\
\hline Keruh & 475 & 470 \\
\hline Keruh & 450 & 440 \\
\hline Keruh & 425 & 415 \\
\hline Jernih & 300 & 295 \\
\hline
\end{tabular}




\section{TEKNO Junal Teknologi, Eektro, dan Kejivuan}

http://journal2.um.ac.id/index.php/tekno | ISSN 1693-8739

Jernih $\quad 280 \quad 270$

\section{PEMBAHASAN}

Dari data diatas didapatkan sebuah penjelasan mengenai tingkat kejernihan dan kekeruhan berdasarkan output PID dan nilai errornya. Dimana nilai analog maksimal-nilai analog minimal dibagi dua sama dengan set point. Set poin juga akan berpengaruh pada hasil tingkat kekeruhannya. Yaitu untuk setting PID maka perlu dikondisikan.

Untuk lebih jernihnya lagi pemakai dapat juga mengeset pada nilai PID 200 dinyatakan jernih. Karena pada PID output $=300$ masih kurang jernih, karena pada sistem tersebut terlihat ketika output PID dan error mendekati set point tingkat kekeruhan juga semakin tinggi, sebaliknya jika tingkat kekeruhan menurun maka grafik respon pada sistem akan menurun atau menjauh dari set point yang telah ditetapkan.

\section{KESIMPULAN}

Berdasarkan penelitian yang telah dilakukan maka didapatkan bebeapa kesimpulan sebagai berikut:Sensor LDR menyatakan air keruh apabila nilai eror dan output PID mendekati set point. Didapatkan nilai tuning PID terbaik pada $\mathrm{kp}=1, \mathrm{ki}=0.2$, $\mathrm{kd}=0.01$, untuk setpoint=518, $\mathrm{Ts}=0.1$, Semakin keruh maka grafik respon akan semakin mendekati set point, sebaliknya akan semakin menjauh dari grafik sensor. Hasil deteksi tingkat kekeruhan air jika water treatment berjalan normal didapatkan angka 2.48 NTU. Dimana standar kemenkes mengenai kekeruhan air yaitu 5 NTU, semakin rendah tingkat NTU maka semakin layak air tersebut untuk dikonsumsi.

\section{REFERENSI}

[1] Hasibuan, Rosmidah. 2016. Analisis Dampak Limbah atau Sampah Rumah Tangga Terhadap Pencemaran Lingkungan Hidup. Jurnal ilmiah “Advokasi”. 4 (1): 42-52

[2] Diana, Kadek dan Konsukartha, I G. M. 2007. Pencemaran Air Tanah Akibat Pembuangan Limbah Domestik di Lingkungan Kumuh. Jurnal Permukiman Natah. 5 (2): 62-168

[3] Wicaksono, S. 2017. Dasar Teori Arduino Uno R3 Arduino Uno R3: http://eprints.akakom.ac.id/3905/3/3_133310002_BAB\%20ll.pdf. Diakses pda tanggal 13 Desember 2017.

[4] Megawati, Arman Y., Trianto D. 2016. Prototype Alat penjernih Air Sumur Otomatis Berbasis Mikrokontroler ATMEGA 8535. Jurnal Coding, Sistem Komputer Untan. 4 (1): 11-20.

[5] Marhi, Z. dan Musyafa, A. Perancangan Kontrol PID untuk Mengatur Tingkat Kejernihan Air Pada Sistem Pengolahan Air Bersih Skala Rumah Tangga. Paper Institut Teknologi Sepuluh Nopember.

[6] Gerry, John. 2005. Adaptive Tunning-Expectations and Limitations. ExperTune Inc.

[7] Mokh. Sholihul Hadi, Syafiq Ubaidilah, Rizky Asillia Puspita Sari, Dwi Puri Fatmala. 2017. Sistem Kendali Otomatis Mesin Penetas Telur Menggunakan Kontroler PID. TEKNO Vol. 27 No 1. 